\title{
Newborn Vaccination and Jaundice
}

\author{
Rawa Al Ameri* \\ Family Medicine Specialist, Al-Mustansiriyah University, Iraq
}

*Corresponding author: Rawa Al-Ameri, Family Medicine Specialist, Al-

Mustansiriyah University, Iraq; Email: dr_rj1983@yahoo.com

\author{
Editorial \\ Volume 2 Issue 3 \\ Received Date: June 07, 2019 \\ Published Date: June 14, 2019 \\ DOI: $10.23880 /$ jqhe-16000124
}

\section{Editorial}

Vaccination of newborn has many controversial issues which are not supported by scientific studies and could be considered as cultural myths but they are still followed in primary health care in the Middle East including Iraq. Despite the major changes that are introduced to the Iraqi Health System by progressing a Family Medicine Board training program but unfortunately this expertise are not used properly. Vaccination is contraindicated, in general; to any condition in a recipient that increases the risk for a serious adverse reaction while a precaution to vaccination is any condition under which vaccines should not be administered [1]. As these contraindications and precautions are temporary, vaccinations often can be given later $[2,3]$.

These contraindications include; Moderate or severe acute illness with or without fever, egg allergy; in certain vaccines as inactivated influenza vaccine; other than hives, e.g., angioedema, respiratory distress, lightheadedness, recurrent emesis.

Progressive neurologic disorder, including infantile sp asms, uncontrolled epilepsy, progressive encephalopathy; History of hypersensitivity reactions after a previous dose $[1,4]$.

Jaundice is usually harmless condition in newborn and mostly no treatment is needed other than breastfeeding as symptoms normally pass within 10 to 14 days and sometimes last longer [5,6].

No reported contraindication to a newborn with jaundice particularly if the newborn is active, feed regularly. Many parents take a choice not to vaccinate their baby will threaten their own and the community's children. Myths regarding jaundice prevent many parents from vaccinating their newborn; unfortunately, many medical staffs take the same point of view which affects the community health. 6 In Iraq the newborn receives at 1st week of life BCG vaccine, Oral Polio the zero doses, and hepatitis $B$ vaccine, which give protection to very endemic diseases. So preventing or delay vaccination will increase the risk of infection with disaster impact on the family and the community [7].

\section{References}

1. (2019) MODULE 2: types of vaccines and adverse reactions. WHO Vaccine Safety Basics. World Health Organization.

2. Halsey NA, Boulos R, Mode F, Andre J, Bowman L, et al. (1985) Response to Measles Vaccine in Haitian Infants 6 to 12 Months Old. Influence of Maternal Antibodies, Malnutrition, and Concurrent Illnesses. N Engl J Med 313(9): 544-549.

3. Siber GR, Werner BG, Halsey NA, Reid R, Hill JA, et al. (1993) Interference of immune globulin with measles and rubella immunization. J Pediatr 122(2): 204-211.

4. Lai J, Fay KE, Bocchini JA (2011) Update on childhood and adolescent immunizations. selected review of US recommendations and literature part 2 Curr Opin Pediatr 23(4): 470-481.

5. (2015) Newborn jaundice - Causes. NHS.

6. Saadat SH, Naderi S, Zare S, Khalili S, Darban B, et al. (2018) Epidemiologic Study of Jaundice in Newborns with Jaundice in the First 24 hours of Birth in Children's Hospital and Shariati Hospital of Bandar Abbas in 2010-2014. J Res Med Dental Sci 6(1): 113117.

7. Al-Lela OQB, Baidi bahari $\mathrm{M}, \mathrm{Al}$-abbassi $\mathrm{MG}$, Salih MRM, Basher AY (2012) Influence of health providers on pediatrics' immunization rate. J Trop Pediatr 58(6): 441-445. 